\title{
Trauma cervical transfixiante por clavo
}

\author{
Transfixed cervical trauma with nail
}

Camila Vergara C. ${ }^{1,2}$, Romina Olmos-de-Aguilera A. ${ }^{3}$, Alfonsina Carrasco D. ${ }^{4}$, Héctor Zagal A. ${ }^{2}$ y Eduardo Sanhueza Z. ${ }^{2}$

\section{Presentación del caso}

Paciente sexo masculino, 32 años, con antecedentes de daño hepático crónico por alcohol, depresión e intentos autolíticos múltiples. Ingresa a Urgencias por herida por clavo en zona II cervical derecha, autoinfligida, con clavo in situ (Figura 1), hemodinámicamente estable. Radiografía muestra clavo bajo hueso hioides (Figura 2). No se dispone de ecografía cervical de urgencia.
Se decide cervicotomía exploradora para extracción del clavo. Se constata herida cervical en zona II derecha, transfixiante, con salida en zona II izquierda. Se realiza incisión arciforme por borde anterior de músculo esternocleidomastoideo (Figura 3 ), identificando lesión de vena yugular anterior derecha y erosión en tráquea sin solución de continuidad. Trayecto del clavo atraviesa músculos platisma bilateral, esternohioideo y omohioideo izquierdos (Figura 4). Se retira clavo de 4" y se liga
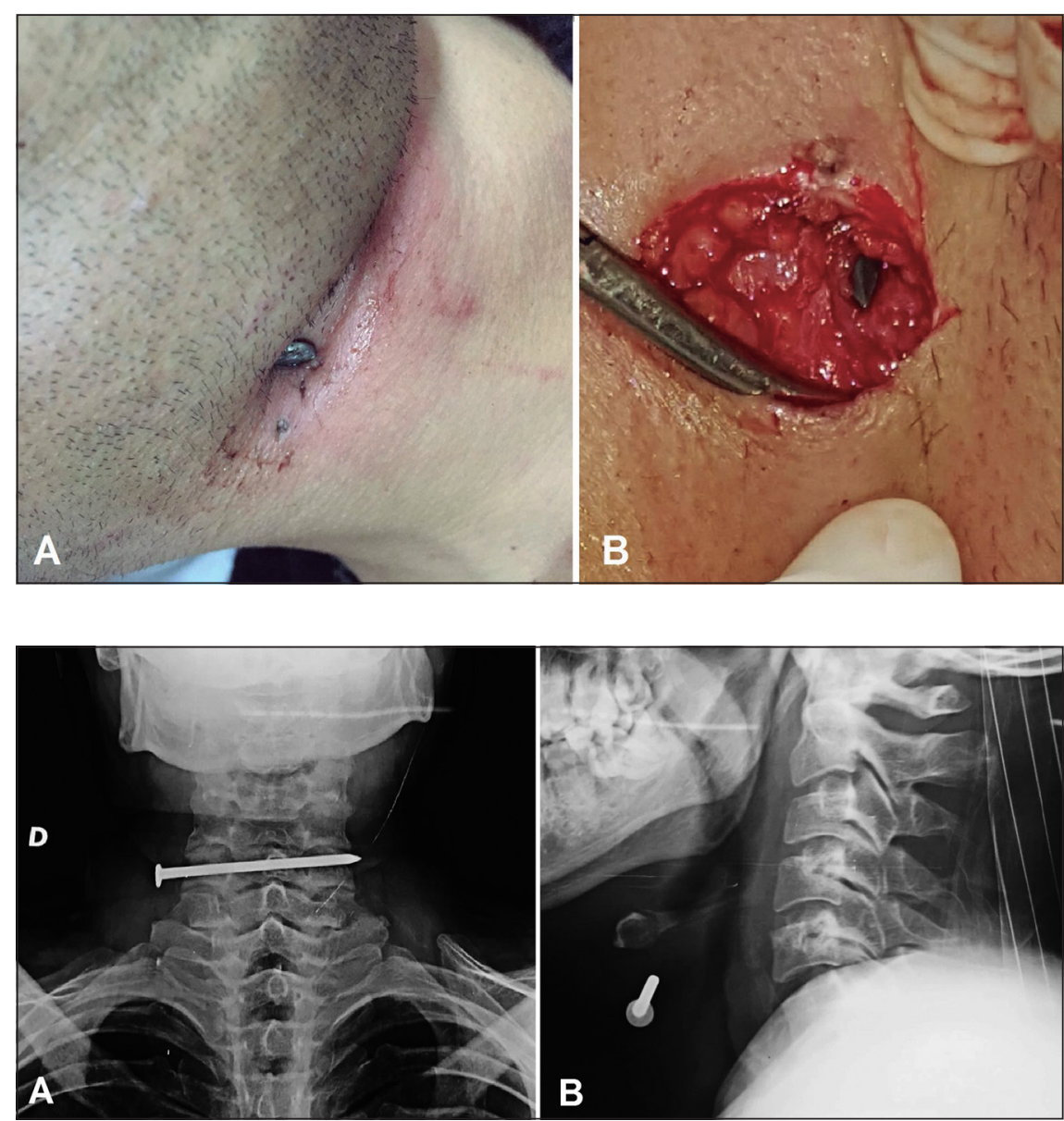

Figura 1. Clavo transfixiante in situ, punto de entrada (A) y salida (B)
'Hospital Clínico Herminda Martín, Chillán.

Universidad Católica de la Santísima Concepción, Concepción.

${ }^{3}$ CESFAM Isabel Jiménez, Tirúa.

${ }^{4}$ Posta Puente Nuble, San Nicolás.

Chile.

Recibido el 30 de mayo de 2017, aceptado para publicación el 11 de agosto de 2017.

Correspondencia a: Dra. Romina Olmos de Aguilera A.

Romi.olmosdeaguilera@ gmail.com
Figura 2. Radiografía cervi cal proyección anteroposterior $(\mathbf{A})$ y lateral $(\mathbf{B})$ 


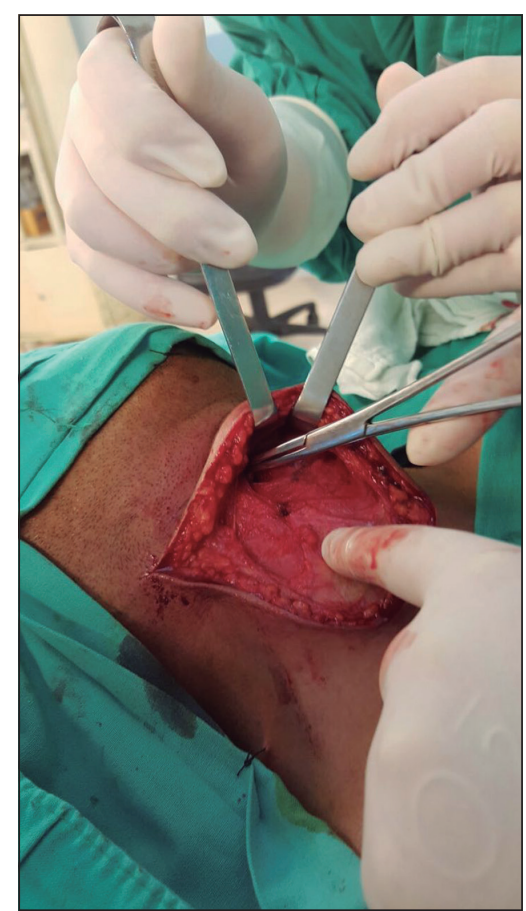

Figura 3. Cervicotomía exploradora con abordaje anterior de cuello.



Figura 4. Cervicotomía exploradora con identificación de clavo in situ.
El manejo está determinado por la necesidad de extracción del cuerpo extraño controlando las posibles lesiones, lo que reduce la morbimortalidad ${ }^{1-3}$. El angioTC es de primera línea en el diagnóstico, sin embargo, el cuerpo extraño metálico in situ provoca hiperrefringencia, siendo posible solo realizar radiografía cervical ${ }^{4-5}$.

\section{Responsabilidades éticas}

Protección de personas y animales. Los autores declaran que para esta investigación no se han realizado experimentos en seres humanos ni en animales.

Confidencialidad de los datos. Los autores declaran que han seguido los protocolos de su centro de trabajo sobre la publicación de datos de pacientes.

Derecho a la privacidad y consentimiento informado. Los autores han obtenido el consentimiento informado de los pacientes y/o sujetos referidos en el artículo. Este documento obra en poder del autor de correspondencia.

\section{Conflictos de interés}

vena yugular anterior derecha. Prueba neumática de tráquea no da salida a aire, procediendo a cierre por planos. Evoluciona favorablemente y se deriva a psiquiatría.
Los autores declaran no tener conflictos de interés.

\section{Bibliografía}

1. Castillo F, Moraga J, Pérez P, Borel B. Trauma cervical penetrante. Rev Chil Cir. 2015;67:584-9.

2. Shatz D, Kirton O, McKenney M, Civetta J. Penetrating neck injuries. En Shatz D, Kirton O, McKenney M, Civetta J, editores. Manual of Trauma and Emergency Surgery. Philadelphia: W. B. Saunders Company; 2000. p. 34-53.

3. Hernández E, Loyola U, Betancourt M, Gómez N, Pérez O, Albores R, et al. Control de daños en trauma penetrante de cuello. Abordaje multidisciplinario. Cir Gen. 2012;34:138-42.

4. Offiah C, Hall E. Imaging assessment of penetrating injury of the neck and face. Insights Imaging 2012;3:419-31.

5. Inaba $\mathrm{K}$, Branco BC, Menaker J, Scalea TM, Crane S, DuBose JJ, et al. Evaluation of multidetector computed tomography for penetrating neck injury: a prospective multicenter study. J Trauma Acute Care Surg. 2012;72:57683. 